\title{
Comparison of Glycaemic control in patients with Type-1 Diabetes Mellitus on CSII therapy with different basal rates
}

\author{
Yunus S, Forde H, Browne S, Moore A, Fanning E, Smith D. \\ Department of Endocrinology and Diabetes Mellitus, \\ Beaumont Hospital, Dublin, Ireland.
}

\section{Background}

- Continuous Subcutaneous Insulin Infusion therapy (CSII) can improve glycemic control in patients with Type-1 Diabetes as observed in several studies.

- However, there are very few studies comparing glycaemic control in patients with different basal rates on CSII, so the ideal number of basal rates for a patient is not clear.

\section{Objective}

- To compare the glycaemic control between patients with different basal rates.

\section{Methods}

- Data was collected from hospital's database (CELLMA) and by contacting patients via phone.



\section{Conclusion}

In our study there was no difference in glycaemic control between the patients on fewer $(<5)$ or more $(\geq 5)$ basal rates. The characteristics of both groups were similar so advice on the optimal number of basal rates for a patient appears to vary from individual to individual. 